\title{
Presenting Educational Measurements so as to Influence the Public Favorably
}

\section{Carter Alexander}

To cite this article: Carter Alexander (1921) Presenting Educational Measurements so as to Influence the Public Favorably, The Journal of Educational Research, 3:5, 345-358, DOI: 10.1080/00220671.1921.10879167

To link to this article: http://dx.doi.org/10.1080/00220671.1921.10879167

册 Published online: 15 Dec 2014.

Submit your article to this journal $[\pi$

Q View related articles $₫$ 
to have a set of questions, preferably the set presented in the assignment, which may be used for self-testing and as a basis for summarizing the material.

\section{DANGERS}

As a sort of summary to what has been said, it may be well to point out certain dangers which must be guarded against particularly.

First, speed exercises are likely to develop a habit of "halfbaked" and careless reading, unless there be a strong emphasis upon comprehension and upon rigorous tests of results attained. Teachers must be urged to keep in mind always that only within the limits of accurate comprehension are speed exercises safe.

Second, there is a danger that an interest in devices and in more or less spectacular methods will weaken the teacher's attack on some of the more prosaic but necessary exercises. Certain devices, such as those which involve following directions and rapid flash card work are novel. Moreover, they make good show lessons. A teacher must keep in mind that her best work will be done with exercises which approximate the sort of reading pupils are most frequently called upon to do in preparing lessons.

Third, there is danger that teachers will use methods which, while attractive, are very uneconomical as methods of learning to read. This is particularly true of such exercises as those in which the pupil constructs something in answer to a reading lesson. The chief value in the construction is its measure as a test of complete comprehension. This is, of course, a real contribution for any exercise to make. Where such a test necessitates construction work extending over a period of 20 or 30 minutes it is clear that, for the purpose of developing ability in reading, the test is very expensive in time.

Fourth, there is a danger that an undesirable consciousness of the process of reading will be developed. In such a case the child goes through the motions of reading very rapidly, but the consciousness of the process operates as a distraction. It is best to avoid asking the pupil to read carefully, or to read accurately, or to read fast, but rather to give such directions as, "Will you find as quickly as you can the answer to this question, 'What are the uses to which peanuts are put'?" Such a question puts the child's attention where it belongs, namely, upon the thought, and will tend to insure the avoidance of any undesirable reading sonsciousness. 

TO INFLUENCE THE PUBLIC FAVORABLY'

\section{Carter Alexander}

State Department of Public Instruction, Madison, Wisconsin

\section{The Situation}

The growth of educational measurements during the past decade, curiously enough, cannot be adequately described in simple numerical terms. We have statistics enough about the number of tests sold, the numbers of books and articles treating of measurements, and the lists of courses in measurement work offered in schools of education and summer sessions. But this growth has been so phenomenal that mere figures are too weak to express it. To do it justice, we need to employ forceful images such as likening it to the gigantic business expansions of the war period.

But the great business concerns have been forced to curtail expansion and to devote their major energies to securing public demand for relatively small outputs. In like manner numerous signs indicate to a thoughtful observer that educational measurements must soon face a similar situation. Effective work in school measurements requires amounts of money which uninformed taxpayers will surely withhold. As a new movement in school work and as an agency certain to secure and to publish the exact facts, it will be early attacked by unscrupulous politicians accustomed to raise the economy cry with reference to public expenditures. To secure adequate financial support, it will be as necessary in the near future for a measurement bureau to convince the taxpayers that it gives unusual value for their money, as it now is for an automobile manufacturer or a clothing merchant to prove that he is offering a superior product at a bargain.

For the sake of better schools it is highly desirable that the educational measurement movement go steadily forward unhampered by lack of necessary financial support. To this end the speaker offers suggestions derived from an extensive study of the claims made for measurement work, as well as of publicity efforts in various school lines and in business salesmanship. Most analyses of successful procedure in publicity and salesmanship

1 Address delivered in part before the meeting of National Association of Directors of Educational Research, Atlantic City, N. J., March 3, 1921. 
stress the use of talking points and the handling of objections. Accordingly, it seems profitable to use this classification here.

\section{Talking Points on Measurement for Strong Appeals TO THE PUBlic}

1. Factual basis.-The average taxpayer, in a time like the present financial stringency, is disposed to fight all appropriation increases. His representatives know this and make a display of voting against heavier taxes. To overcome such opposition, a cause must rely upon one or more of three supports. It must show a powerful emotional appeal, it must demonstrate that it is backed by an array of votes not safely to be ignored by a politician, or it must present its needs with such sound and exhaustive exhibits of facts that no reasonable voter can refuse its requests. School measurement work at present cannot hope to arouse much emotional support, although there should in time be a chance to exploit the very excellent work now being done in giving neglected children individual attention through disclosures made as a result of measurement work. Some of the items on work for neglected individuals reported at this convention have all the emotional possibilities that even a welfare worker of the "sob" school could desire. At present measurement work has little chance to secure support through popular votes. But it deals with facts as does no other phase of school work. It has an enviable opportunity to show a hard-headed business man or taxpayer that its requests for money are founded upon a minimum of theory and a maximum of facts. It can evolve a presentation based upon facts that cannot be really opposed and that can be answered only by evasion. It is thoroughly equipped to show up such evasion for precisely what this procedure is worth.

2. Definiteness and finality.-The average citizen interested in education does not care for vague general criticisms of school work. He distrusts elaborately qualified evaluations. $\mathrm{He}$ has no patience with the type of scientific "hedging" so often heard at our measurement discussions, "these conclusions are only tentative," or "this is probably the safer hypothesis unless so-andso should prove to be true, which cannot be fully established until further investigations are made." Such cautious statements, while indispensable at scientific meetings, only incite his ridicule. $\mathrm{He}$ desires a direct authoritative statement of what is really known. If a thing is uncertain, it had in his opinion better not 
be mentioned. He desires this statement to be clean-cut and often prefers it expressed in approximate numerical terms. Measurement work can point out the particular grade in a school system that needs special attention. It can state that the work in this grade is weakest in a certain subject. It can specify, for instance, that the arithmetic shows better results in speed than in accuracy. It can analyze the fundamental processes involved and show just which ones need strengthening. It can show how any such record compares with a standard or with work in comparable schools. All such things can be done with greater definiteness and finality by measurement work than by any other form of supervision.

3. Brevity.-In regard to school needs, the average citizen is like the Yale students who were never converted by any sermon after the first twenty minutes of it. He is not apt to be converted to increased school taxes after the first twenty minutes of any given effort. Measurement work, by virtue of its power to express its summaries and comparisons in statistical terms, has a distinct advantage in the public presentation of its needs over many other phases of school work. A measurement bureau, for instance, ought to be able to prove the case on any reasonable school need for more money in a fraction of the number of pages or lines of type necessary for many other school workers who might try to prove the same case.

4. Impersonality.-Theoretically, measurement work makes its studies with less personal bias or pre-judgments than any other kind of educational investigation. In actual practice measurement work sometimes appears to attempt to measure phases of school activity that are not easily or profitably subjected to numerical treatment, and to stress formal matters unduly. But if measurement workers are reasonably careful and use plenty of common sense, they can justly claim a very strong talking point for their pronouncements. They can be less successfully accused of sweeping statements, of hasty conclusions, and of hobby-riding than can any other persons attempting to evaluate school work. Their standards and procedures are of ten so simple that they can easily set a pupil to measuring for himself his own progress in school work.

5. Prestige of up-to-dateness.-A final talking point grows out of the fact that measurement work is now generally regarded in leading educational circles as one of the earmarks of an up-to- 
date school system. If there is no unjust depreciation of the work of those who were making careful quantitative studies before the term "measurement" came into general use, this prestige value can be played up to great advantage. Teachers and communities may be frankly somewhat skeptical on many phases of measurements. But if the suggestion has been skillfully made that those opposing measurement work are thereby in danger of being considered unprogressive, many people will hesitate to oppose it. Much of the present vogue of measurement work undoubtedly. is due to skillful exploitation of this particular prestige value. This talking point of course is more useful now than it will be after some years.

\section{OBJECTIONS}

In good business organizations, salesmen are coached not only on talking points but on all possible objections. They are not to bring up objections, but they are to be ready to utilize any that may arise. The former sales manager of the Ford Motor Company in his books on salesmanship takes great pains to elaborate the view that an objection if real is a sign of interest on the part of the customer. $^{2}$ Briefly, the analysis runs thus: A possible customer does not take the trouble to object to a thing which has not attracted his serious attention. The objection is a sign of energy or attention to the proposition. It is the salesman's business by a skillful presentation of his case to divert this energy rather toward than against the proposition.

What, then, in the mind of the public, are the chief objections to measurement work for which the director of measurements should be prepared?

1. Measurement work is too costly for the results secured.From the available literature and from fairly numerous reports, it is certain that in the present flush of enthusiasm some measurement workers have forgotten that the public will judge their activities by the same economy standards which they employ in evaluating school work. Any well-developed measurement bureau attempts to determine whether money for schools is economically spent and suitably apportioned according to the importance of the various phases of school work. The taxpayer is easily interested in the results of such analysis. He is certain to object to putting more money into measurements until he sees how this measurement work appears under the same kind of

${ }^{2}$ Hawkins, Norval A., The selling process, chap. $\mathbf{x}$. 
analysis. The measurement bureau should accordingly be prepared to show that its own expenditures are justified. It spends some money and it consumes time and energy of both teachers and pupils. This time and energy represent the same cash value when expended upon measurements as when devoted to arithmetic or the keeping of school records. The measurement bureau must be ready to show better results for such cash equivalent than would have been secured by the regular school work that would otherwise have gone on. If approximately the same results can be secured with a twenty-minute test as with a forty-minute one, or with a battery of tests instead of with many different tests, or if a five-cent test will do instead of a ten-cent one, or if the clerical labor involved in one is only a fraction of that needed for a similar test, or if a rough oral test will suffice for an elaborate written one, the bureau should do the economical thing and advertise the fact.

Sometimes measurements produce only results that any careful, experienced observer in the system could have secured with a fraction of the money, time, and energy necessary to secure them through measurements. In such a situation the expenditures for the measurement work can best be defended by playing up impersonality values and uses for convincing incompetent but obstinate teachers of their incompetence.

It is, however, easy to make out a very strong case for the economies possible under the right kind of school measurement work. An examination of only the first ten numbers of the JoURNAL OF EDUCATIONAL RESEARCH and a few other periodicals indicates such economies as the following. To save space, only the volume and page references are given. Unless otherwise specified, the reference is to the Journal of EDUCATIONAL RESEARCH.

a. A much more accurate knowledge of individual abilities of pupils which may be utilized to let brilliant pupils out of work they do not need $(2: 12,13)$; to enable the teacher to know in 90 percent of cases just what each pupil needs (2: 620); to detect cases of shamming and laziness in pupils (2:12); to reduce failures in high schools through superior guidance by teachers $(1: 380)$; to make more serviceable reports to parents as to their children's needs (American School Board Journal, February, 1921, p. 62 ; Educational Review, 59, p. 346). 
b. The choosing of much better texts and the paying of prices necessary to secure suitable texts $(1: 119,222-24 ; 2: 671)$.

c. Better time allotments for subjects (2:736-40).

d. The saving possible by increasing the rate of speed in silent reading $(1: 136)$.

e. The actual cost of short terms and poor teaching in rural schools $(1: 271 ; 2: 636 \mathrm{ff})$.

2. Some measurement workers do not seem to use enough common sense.-Friends of the measurement movement, to say nothing of uninformed or hostile persons, feel that measurement workers sometimes exhibit a great deal of clerical and mechanical activity with insufficient thought and common sense. This is the idea back of Monroe's observation that teachers often consider tests as teaching devices and express dissatisfaction that pupils do no better after them. ${ }^{3}$ It was also in the mind of the intelligent man who told Ashbaugh that bureaus of reasearch so far had been simply "accounting" bureaus. ${ }^{4}$

Now, in ordinary life we object that taking snap judgment is unfair. But all of us know that in some schools children are being assigned to grades or promoted largely on the basis of one brief intelligence test- "in twenty minutes branded for life" as one keen observer recently put it. A capable school man without any direct knowledge of measurements told the speaker recently of the case of his two boys in a school system with which the man had no connection. Last year in this system half-yearly promotions were started. The pupils for the higher sections were selected by taking the results of one intelligence test, given carefully under expert supervision before Christmas. On the basis of this test one of the man's sons was promoted and one held back. Later in the year another similar test was given with equal care. The advanced boy was then pronounced average and the boy who had been held back was then said to be very intelligent. 'The father has made every allowance of which he can think, but naturally he wonders what it was all about. A trained measurement worker knows that occasional errors of this sort are inevitable; but it is very difficult to bring the ordinary man to this point of view, much less to induce him to vote more money for such work.

Common sense is indicated by frankly recognizing that there are still many phases of school work where measurements cannot 
be profitably used. In some cases they probably never can be. Then, too, judgment needs to be exercised in the applications of results. Per capita costs, for instance, are very valuable in their place, but of little value for final pronouncements on upper classes, new departments, or elective courses, especially in small schools.

In Wisconsin we often wonder where the common sense was when the recent Ayres report on state school systems was compiled. The speaker has the greatest respect for the high purpose behind this great pioneer effort in educational research, as well as for the conspicuous ability that planned and executed the report; but the failure to use common sense in some places has materially lessened the value of the report to us in Wisconsin. From an educational campaign standpoint, nothing could be simpler than employing the social psychology involved in the fact that Wisconsin ranks thirty-third on this list and state pride wishes her to be near the top on any commendable list. But this campaign procedure is impossible because careful readers of the report, whether they are school men or not, are soon struck with the fact that certain important elements have been altogether omitted. The report, it will be recalled, attempts to measure just two things, attendance secured at public elementary and high schools, and expenditures upon these schools.

On the attendance basis Montana, the first state on the general list, is credited with a huge school enrollment which has been said by the United States Bureau of Education to be largely due to unusual immigration since the 1910 census. The Canal Zone, which gets only one-fourth of its children into school, has a higher index by several places than does Wisconsin where half the children are in public schools, to say nothing of many more in parochial schools. In the general list Wisconsin, with an illiteracy rate of 32 per thousand for those ten years of age and over, is thirty places below Arizona which has a rate of 209 per thousand for the same ages. From a common sense standpoint literacy in these ages would show about as clearly as anything the real results of public school work.

Although half the emphasis in the report is upon expenditures for public elementary and high schools, any account of money spent upon training teachers for these schools is omitted. Thus Wisconsin draws thirty-third place in the general list, notwithstanding the fact that, as nearly as we can figure, she spent in the year considered more money upon the training of teachers than 
the first three (possibly four) states in the list combined, although, taken together, they had something like three times her population and about three times her wealth. From a common sense standpoint such a ranking procedure is similar to that of a physician who would attempt to pronounce upon the health of a man by examining only the lungs and the digestive and excretory organs with no attention to the heart or circulatory system.

It is only fair to state that part of the extraordinary ratings assigned to Wisconsin came about because of a misunderstanding of the data in the state reports to the United States Bureau of Education which were used for the report. Here common sense would have led one to suppose that staffs of state departments of public instruction lost the services of members assigned to war service and had changes in personnel which would make the reports on this period at best somewhat doubtful. Common sense would also have avoided adding in the total number of teachers for Milwaukee (something over 10 percent of the teaching staff of the state) while omitting in some of the calculations all the expenditures for their salaries, which are naturally the highest in the state. Certainly, common sense would have suggested that school data collected for the year 1918 with all the disruption of school systems in that year, ought to be visèd before publication by the only persons competent to eliminate such an error. If only the common sense device used by Flexner in his study of medical schools for the Carnegie Foundation had been used, much of the trouble could have been cleared up before publication. Flexner's study was practically impregnable because he was able to say that his every statement about a medical school had been submitted to the school in question and this school had been given full opportunity to disprove it or to demonstrate what modification ought to be made before publication.

It is only fair also to state that the Ayres report accomplished considerable good by focusing attention upon the plain facts that Wisconsin does not spend enough money upon her public schools and does not secure a good enough school attendance. But the failure to allow for the elements mentioned resulted in more use of the report by politicians, educational factions, and spiteful busybodies than by school men.4a Had the report been able to

${ }^{4}$ Since this address was delivered, the defeat of Superintendent Cary of Wisconsin for re-election in a campaign in which this report was extensively used against him, furnishes an interesting example of the uses to which such a report may be put. Although 
withstand the common sense test, it would have been worth several times as much to us in Wisconsin.

In a recent number of the Journal of Educational ReSEARCH there appeared

A list of states whom use of tests hath blest

And lo, Wyoming's name led all the rest. ${ }^{5}$

As we are always on the watch in Wisconsin to analyze the secrets of success elsewhere in order that we may better our own work, we looked into this situation. According to the article the states were ranked on the basis of "systematic use of standard tests in cities of ten thousand population or over." Wyoming had a rating of 80 percent on this, counting five cities as in this class. The large number of such cities in Wyoming seemed unusual and the back of the well-known book company calendar credited the state with only one city that large in 1920. Later it was found that the ranking had been made from data given in a previous article in the same journal by another writer who had attempted no such ranking. The latter, in addition to writing to cities of 10,000 or over, sent letters in the country at large "to a few cities of less than 10,000 population where there was special reason for thinking that research work had been provided for." Every precaution may have been taken to safeguard this procedure scientifically so that all states would be fairly treated in this supplementary list. It, however, resulted in adding four cities to the original one city of Wyoming. If additional cities for Wisconsin had been chosen on the basis of the same extension of census limits alone, at least twenty additional cities would have come in for this one state. The addition of the small cities in the manner used may be explained and possibly justified to trained measurement men save

carefully labeled "An Index Number for State School Systems," the study was popularly known throughout the state simply as "The Ayres Report." The defeat of Superintendent Cary by 29,939 votes in a total of 385,003 appears in the light of careful inquiry by the writer to be due to the determined opposition of three groups: (1) rural taxpayers disgruntled over the state superintendent's condemnation of disreputable school buildings and his agitation for living salaries for teachers; (2) powerful parochial school organizations representing two faiths; (3) manufacturers who raised a large campaign fund against him because he uncompromisingly opposed exploitation of the regular public school system by employers interested primarily in vocational training.

No one of these three groups has ever been accused of desiring to increase taxes for regular public schools or attendance at them. Yet only by increases in these two items could the state's standing in the report possibly be raised, no matter who was state superintendent or what his policy might be. 'Journal of Educational Research, 3:72. 
for the distortion liable to be caused by running component percents on very small groups. But the ordinary man looking at the matter from a common sense standpoint is not apt to see this. In his mind, to balance the addition of four cities for Wyoming, cities would have to be added by the dozen for some other states.

The measurement movement is facing a serious problem in regard to the common sense likely to be exhibited by many of the new measurement workers. The leaders in the movement so far have in the main been men and women of considerable actual experience in teaching who later added their measurement equipment. They have thus been able to make valuable interpretations and applications of their measurements. Now, however, the educational institutions are sending out many youngsters highly trained in measurement technic but sometimes woefully ignorant of the school work which they are attempting to measure. The more gifted of these will, of course, soon recognize their limitations and in time will undoubtedly overcome this handicap by hard work. But where many of them will get the common sense necessary to make their interpretations and pronouncements really valuable is indeed a problem.

3. Too little constructive help is given after tests.-Probably no experienced measurement worker would claim for a minute that public school systems should do any measurement on their own account except for constructive supervision. Some superintendents, of course, do measurement work in their schools for their graduate theses; but most of these sincerely believe that they are materially bettering the regular school work by such studies. Every progressive school system expects to share in aiding fruitful measurement research carried on by the higher education agencies in its territory. But even here the expectation is that the results will be sufficiently valuable to the local system to justify the time given to the work. Most of the measurement literature in the Journal of Educational REsEARCH stresses the view that measurement is merely for results whose interpretations and applications are of material aid to the schools tested.

But notwithstanding all these good intentions, in altogether too many cases the measurement work stops short of giving the expected help to the schools tested, and certainly it stops short of making adequate recompense for the expenditures on the work. In Wisconsin, for instance, in some counties supervising teachers are devoting much of their time to visiting teachers who are giving 
tests. Then they stay in the office to work up the results which they send to the inexperienced girls in the rural teaching positions. Much of this work is extremely valuable. But the public in many places is not yet convinced that it can produce better results than the same time expended in demonstration teaching by the supervisor, in observing the teacher's work, and in giving the latter helpful personal suggestions and criticisms. From all over the country come reports of so much testing by some teachers that insufficient time is left for the actual teaching. An intelligent and progressive city superintendent in all sincerity recently remarked that he could not see why so much testing was done for silent reading work when measurement workers say there is a very high correlation between silent reading ability and intelligence. That is, he had not seen that the testing had resulted in more than saying that the naturally intelligent children would do the best silent reading anyway. At our Wisconsin City Superintendents' Convention last October, a very capable superintendent, one who tries to keep up with every school improvement, said publicly that the testing for silent reading and the emphasis upon securing better results in it seemed likely to end in dropping literature and the oral reading necessary for the appreciation of poetry and the finest prose almost wholly out of the course of study. In his thinking the loss of an appreciation of literature could not be offset by any gain in silent reading for mere information. At a conference some time ago a leading educator expressed doubt as to the value of so much testing for promotion purposes when a very high correlation has been shown between the results of good intelligence tests and the opinions of competent teachers as to which children should be promoted. No doubt the skilled measurement workers have excellent reasons for their procedure and can, fairly easily, answer such objections. But the point here is that such objections from thoughtful people ought to be guarded against in advance as much as possible.

These and similar observations of competent practical school men indicate the great work yet to be done in emphasizing that the interpretation and application of results are of chief importance. Part of the difficulty doubtless arises from the comfortable definiteness of the mechanical processes involved in the measurement work. Most teachers are like most people; they do not care for the strain involved in what we call creative or purely original work. Interpretations, applications, and definite outlining of 
remedial measures form the hardest kind of work, a kind actually painful to many people. But the tests are worked out with such explicit directions by the makers that the giving of tests, scoring, and compilation of results are routine work necessitating little real mental effort. The teachers are perfectly willing to devote any amount of time to this and really think they are achieving something. Whether this is really the case or not, all measurement workers need to measure their own efforts to see what actual help comes to the schools from it. And they will need to convince the public that this help is an adequate return for the expenditures involved. This should be a fairly simple matter for it seems only reasonable to suppose that a measurement worker should be able to evaluate and improve his own work more easily than can any other kind of school man.

4. The style of presentations of measurements for the public should be radically different from that for fellow measurement workers.Probably no one would contend for a moment that the style ought to be the same for the two groups. Certainly the National Association of Directors of Educational Research would not. They have already made a distinction between their association meetings and their open meetings. They also know that the public as a whole has only about the reading ability of a fifth-grade child. But the fact remains that there are still too many measurement bulletins and measurement sections of surveys which appear to have been written with one eye on fellow workers and the other eye on the public. Such publications, unless very skillfully presented, can influence the average taxpayer only as he has respect for something which he thinks is beyond him. Such an attitude on his part is not apt to make him advocate more money for the work.

In this connection we may take advantage of the experience of the United States Department of Agriculture and of the various university extension organizations. These long ago found that the style of matter intended for the public must be radically different from that for fellow scientists. These organizations issue bulletins for scientists and then interpret and explain the same things in public bulletins of a very different nature. In educational work there are a few examples like the publications of Dr. Ayres for the Russell Sage Foundation which are effective with both groups. But in the main, the practice of separate publications is much better. 
Form elements in material for the public merit special emphasis. Presentations for the public should translate statistical results by taking advantage of ideas already understood by the average man and by utilizing purely local illustrations. Many people have the essentials of statistical ideas ready for measurement workers to utilize. Thus the speaker a year or two ago ran across an old deer hunter who was talking of the refusal of some city hunters to wear red caps or coats. They said it was dangerous because far more men were shot who wore red than who did not. The old hunter had the correct statistical idea when he remarked that because practically all deer hunters wore red, more wearers of red would be sure to be shot anyway. Again, in Birmingham, Alabama, years ago someone laid down the regulation that the passing mark in any class was to be 10 percent below the class average calculated from grades on a scale of one hundred. The author of this rule, and all teachers following it, had certain very important statistical ideas all ready for measurement work to start with.

Spending energy on translating measurement results into forceful images familiar to the local public is profitable work. Thus in Wisconsin, in securing support for county training schools last year, we showed that the typical tax burden for county support was the price of one egg per thousand dollars of assessed valuation for each year. This year, in order to have finer divisions, we have employed the price of milk to the farmers at the condenseries. Thus we have been able to show that in one very wealthy county, the county training school has cost the equivalent of one-half pint of milk per thousand dollars of assessed valuation for the year. This fall a Wisconsin county superintendent, in a county where many miles of cement road are being built, discomfited the advocates of low school taxes by pointing out that the cost of rural schools in his county for the year was just equal to that of two miles of cement road.

Time is not available for an extended treatment of other useful matters of form, which have been treated at length elsewhere by the speaker. ${ }^{6}$ But certain items merit listing. For public presentation, each statistical table should preferably express but one idea. The printing should be easily read from one position. The print should be large enough to avoid eye fatigue, especially on the part of older and influential taxpayers. The data in tables should be

- Alexander, Carter. School statistics and publicity. 
shifted from an alphabetical or other purely arbitrary arrangement so as to bring out their sequences. Forceful graphs and pictures may be used to illustrate definite points and should be so labeled as to be easily intelligible by themselves. Material so labeled is of special value for lantern slides to be used in presenting measurements at various public meetings. The tables in the educational reports of the Russell Sage Foundation are excellent models for this. It is well to note that advertisements, which often contain statistical matter, use graphs very sparingly. In much measurement publicity the best results will probably be secured by a series of brief presentations issued at intervals, each fairly complete in itself but forming an essential part of a well-planned whole. If the whole presentation must be printed at one time, the conclusions and recommendations should be printed at the first with the extended proof in later sections. An admirable example of this is the recent study by Dr. G. H. Reavis. ${ }^{7}$ The first twenty-five pages are very interesting and stimulating to the average man. The statistical foundations for these statements, elaborated to suit the most exacting statistician, appear in subsequent sections.

\section{AN UnderdeVELOPED Field}

According to an editorial by Terman, "History shows that when poverty-stricken schools face insistent demands for higher efficiency the result is likely to be a development along the lines of inner organization, method and procedure." 8 Our public schools with their rapidly increasing demands for money are in many places poverty-stricken, or they soon will be. On all sides we feel insistent demands for higher efficiency in school work. Measurement work will play the leading rôle in the inner development sure to take place. But such development at best can accomplish little compared to what may be done if reasonable increases in school support can also be secured. Measurement workers are prepared as are no other school men to present educational needs to the public so that better school support may be obtained. But the measurement energy so far has mainly attacked problems of inner development. The members of this association of course desire to be true educational patriots. To attain this wish, they must do their fair share of the fighting necessary to secure better school support.

${ }^{7}$ Factors controlling attendance in rural schools. (Teachers College, Columbia University, Contributions to Education, No. 108.)

Journal of Educational Research, 1:138. 